\title{
Current landscape of immunotherapy in the treatment of solid tumours, with future opportunities and challenges
}

\author{
N.A. Nixon $\mathrm{MD}^{*}{ }^{*} \mathrm{~N}$. Blais $\mathrm{MD}_{1}^{\dagger}$ S. Ernst $\mathrm{MD}_{1}^{\ddagger}$ C. Kollmannsberger $\mathrm{MD},{ }^{\S}$ G. Bebb BM BCh PhD, ${ }^{*}$ \\ M. Butler MD, M. Smylie MD, ${ }^{\#}$ and S. Verma MD*
}

\begin{abstract}
Immunotherapy has emerged as a new standard of care, showing survival benefit for solid tumours in multiple disease sites and indications. The survival improvements seen in diseases that were highly resistant to traditional therapies, with a poor prognosis, are unprecedented. Although the benefits observed in clinical trials are undeniable, not all patients derive those benefits, leading to emerging combination strategies and an ongoing quest for biomarker selection. Here, we summarize the current evidence for immunotherapy in the treatment of solid tumours, and we discuss emerging strategies at the forefront of research. We discuss future challenges that will be encountered as experience and knowledge continue to expand in this rapidly emerging field.
\end{abstract}

Key Words Immuno-oncology

Curr Oncol. 2018 Oct;25(5):e373-e384

www.current-oncology.com

\section{INTRODUCTION}

Harnessing the body's ability to mount an immune response against tumour cells is now a well-established strategy to treat cancers. For many years, it has been known that the immune system can help to treat cancer; however, initial attempts to utilize its potential did not translate into widespread use. Recently, interest in this strategy has been increasing as a result of the great successes seen in melanoma, non-small-cell lung cancer (NSCLC), and genitourinary cancers, among others. As understanding of the interaction between tumours and the immune system increases, novel therapies with sophisticated mechanisms of action are becoming standards of care. Here, we review the immunotherapies currently available to treat cancer, the emerging strategies, and the practical implications as evidence is translated into clinical practice.

\section{SUMMARY OF CURRENT THERAPIES}

In recent years, a number of practice-changing clinical studies have reported on immunotherapies. Since the initial success of ipilimumab in metastatic melanoma, immune checkpoint inhibitors have changed the landscape of systemic therapy for advanced disease in many solid tumour types. Table I summarizes key phase III studies in many cancer subtypes, including lung, head-and-neck, renal, urothelial, and gastric cancers and melanoma.

Melanoma has a long history of response to immune manipulations and its immunotherapies are now at the forefront of approved strategies and those in clinical trials. Interleukin 2, a cytokine that affects the cytotoxic functioning of $\mathrm{T}$ cells and the maintenance of $\mathrm{T}$ regulatory cells, was one of the first immunotherapies to be used in advanced disease ${ }^{21}$. Although response rates were modest, durable responses were observed, suggesting the possibility that some patients were "cured." However, widespread use of interleukin 2 was limited by significant toxicity. Ipilimumab was the first checkpoint inhibitor to demonstrate a survival benefit in metastatic melanoma (Table $)^{1}$. Ipilimumab is a fully humanized immunoglobulin $\mathrm{G}$ monoclonal antibody that prevents the CTLA-4 protein from binding its ligand, with the net result of preventing its inhibitory effect on T-cell activation. Building on those results, anti-PD-1 antibodies were developed as the next immune checkpoint blocking agents, and those agents have continued to improve outcomes, with less toxicity. The PD-1 receptor protein, expressed on T cells, B cells, and natural killer cells, binds to its ligand (PD-L1), expressed on stromal and tumour cells, to downregulate the immune response. 
TABLE I Summary of immunotherapy trials leading to approvals by the U.S. Food and Drug Administration and Health Canada in metastatic solid tumours

\begin{tabular}{|c|c|c|c|}
\hline Disease site, agent, and line & Reference & Regimen & Outcome \\
\hline \multicolumn{4}{|l|}{ Melanoma } \\
\hline \multicolumn{4}{|l|}{ Ipilimumab } \\
\hline \multicolumn{4}{|l|}{ First line } \\
\hline & Robert et al., $2011^{1}$ & Ipilimumab (3 mg/kg) & mOS: \\
\hline & & plus dacarbazine & 11.2 vs. 9.1 months \\
\hline & & vs. dacarbazine & (HR: $0.72 ; p<0.001)$ \\
\hline \multicolumn{4}{|l|}{ Second line } \\
\hline & Hodi et al., $2010^{2}$ & Ipilimumab & mOS: \\
\hline & & vs. gp100 antigen & 10 vs. 6.4 months \\
\hline & & & (HR: $0.68 ; p<0.001)$ \\
\hline \multicolumn{4}{|l|}{ Pembrolizumab } \\
\hline \multirow[t]{4}{*}{ First line } & Robert et al., $2015^{3}$ & Pembrolizumab & 1-Year OS: \\
\hline & (KEYNOTE-006) & (10 mg/kg every 2 or 3 weeks) & $74.1 \%$ vs. $58.2 \%$ \\
\hline & & vs. ipilimumab & (HR: $0.63 ; p=0.0005)$ \\
\hline & & (3 mg/kg every 3 weeks) & \\
\hline \multirow[t]{3}{*}{ Second line } & Ribas et al., $2015^{4}$ & Pembrolizumab & $(* *$ measure?**): \\
\hline & (KEYNOTE-002) & (10 mg/kg) & 14.7 vs. 11.0 months \\
\hline & & vs. chemotherapy & \\
\hline \multicolumn{4}{|l|}{ Nivolumab } \\
\hline \multirow[t]{5}{*}{ First line } & Robert et al., $2015^{5}$ & Nivolumab (3 mg/kg) & 1-Year OS: \\
\hline & (CheckMate 066) & vs. dacarbazine & $72.9 \%$ vs. $42.1 \%$ \\
\hline & & & (HR: $0.42 ; p<0.001)$ \\
\hline & & & Updated 2-year OS: \\
\hline & & & $5.5 \%$ vs. $26.7 \%$ \\
\hline \multicolumn{4}{|l|}{ Nivolumab plus ipilimumab } \\
\hline \multirow[t]{8}{*}{ First line } & Larkin et al., $2015^{6}$ & (A) & mPFS: \\
\hline & (CheckMate 067) & Nivolumab (1mg/kg) & 11.5 vs. 6.9 vs. 2.9 months \\
\hline & & plus ipilimumab (3 mg/kg) & [HR (A vs. C): $0.42 ; p<0.001]$ \\
\hline & & every 3 weeks & Updated OS (AACR 2017): \\
\hline & & (B) & NR vs. NR vs. 20.0 months \\
\hline & & Nivolumab (3 mg/kg) & [HR (A vs. C): 0.55] \\
\hline & & (C) & \\
\hline & & Ipilimumab (3 mg/kg) & \\
\hline \multicolumn{4}{|l|}{ Non-small-cell lung cancer } \\
\hline \multicolumn{4}{|l|}{ Nivolumab } \\
\hline \multirow[t]{6}{*}{ Second line } & Brahmer et al., $2015^{7}$ & Nivolumab (3 mg/kg) & mOS: \\
\hline & (CheckMate 017, SCC) & vs. docetaxel & 9.2 vs. 6.0 months \\
\hline & & & (HR: $0.59 ; p<0.001)$ \\
\hline & Borghaei et al., $2015^{8}$ & Nivolumab (3 mg/kg) & mOS: \\
\hline & (CheckMate 057, non-SCC) & vs. docetaxel & 12.2 vs. 9.4 months \\
\hline & & & (HR: $0.73 ; p=0.002$ ) \\
\hline \multicolumn{4}{|l|}{ Pembrolizumab } \\
\hline \multirow[t]{3}{*}{ First line } & Reck et al., $2016^{9}$ & Pembrolizumab (200 mg) & mPFS: \\
\hline & (KEYNOTE-024, & vs. platinum-based & 10.3 vs. 6.0 months \\
\hline & PD-L1 $\geq 50 \%)$ & chemotherapy & (HR: $0.50 ; p<0.001)$ \\
\hline
\end{tabular}


TABLE I Continued

\begin{tabular}{|c|c|c|c|}
\hline Disease site, agent, and line & Reference & Regimen & Outcome \\
\hline \multicolumn{4}{|l|}{ Non-small-cell lung cancer continued } \\
\hline \multicolumn{4}{|l|}{ Pembrolizumab } \\
\hline \multirow[t]{4}{*}{ Second line } & Herbst et al., $2016^{10}$ & Pembrolizumab & mOS: \\
\hline & (KEYNOTE-010, & [(A) $2 \mathrm{mg} / \mathrm{kg}$ or & (A) 10.4 vs. (B) 12.7 \\
\hline & excluded PD-L1<1\%) & (B) $10 \mathrm{mg} / \mathrm{kg}]$ & vs. (C) 8.5 months \\
\hline & & (C) Docetaxel & [HR (B vs. C): $0.61 ; p<0.001]$ \\
\hline \multicolumn{4}{|l|}{ Atezolizumab } \\
\hline \multirow[t]{3}{*}{ Second line } & Rittmeyer et al., $2017^{11}$ & Atezolizumab & mOS: \\
\hline & $(\mathrm{OAK})$ & vs. docetaxel & 13.8 vs. 9.6 months \\
\hline & & & (HR: $0.73 ; p=0.0003)$ \\
\hline \multicolumn{4}{|l|}{ Head-and-neck cancer } \\
\hline \multicolumn{4}{|l|}{ Nivolumab } \\
\hline \multirow[t]{3}{*}{ Second line } & Ferris et al., $2016^{12}$ & Nivolumab & mOS: \\
\hline & (CheckMate 141) & vs. treatment of & 7.5 vs. 5.1 months \\
\hline & & physician's choice & (HR: $0.7 ; p=0.01)$ \\
\hline \multicolumn{4}{|l|}{ Pembrolizumab } \\
\hline \multirow[t]{4}{*}{ Second line } & Seiwert et al., $2016^{13}$ & Pembrolizumab & ORR: $16 \%$ \\
\hline & (KEYNOTE-012) & & CR: $5 \%$, with a durable \\
\hline & & & response $>6$ months \\
\hline & & & in $82 \%$ of responders \\
\hline \multicolumn{4}{|l|}{ Urothelial cancer } \\
\hline \multicolumn{4}{|l|}{ Atezolizumab } \\
\hline \multirow[t]{4}{*}{ Second line } & Powles et al., 2014 & Atezolizumab & ORR: $46 \%$ \\
\hline & & & (PD L1 IHC 2/3) \\
\hline & & & mPFS: 24 weeks \\
\hline & & & (PD-L1 IHC 2/3) \\
\hline
\end{tabular}

Nivolumab

Second line
Sharma et al., $2017^{15}$

(CheckMate 275)
Nivolumab (2 mg/kg)

RR: $19.6 \%$

(28.4\%, PD-L1>5\%;

$23.8 \%$, PD-L1>1\%;

$16.1 \%$, PD-L $1<1 \%$ )

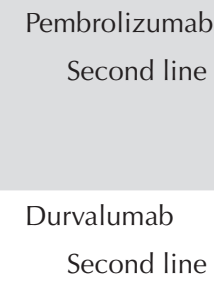

Durvalumab

Second line

Bellmunt et al., $2017^{16}$

(KEYNOTE-045)

Pembrolizumab

vs. chemotherapy

mOS:

10.3 vs. 7.4 months (HR: $0.73 ; p=0.002$ )

Powels et al., $2017^{17}$

Durvalumab

6-Month PFS: 24\%;

1-Year PFS: $17 \%$

mOS: 14.1 months

Renal cell carcinoma

\begin{tabular}{|c|c|c|c|}
\hline \multicolumn{4}{|l|}{ Nivolumab } \\
\hline Second line & Bellmunt et al., $2017^{16}$ and & Nivolumab (3 mg/kg) & mOS: \\
\hline & Motzer et al., $2015^{18}$ & vs. everolimus & 25.0 vs. 19.6 months \\
\hline & (CheckMate 025) & & (HR: $0.73 ; p=0.002)$ \\
\hline
\end{tabular}


TABLE I Continued

\begin{tabular}{|c|c|c|c|}
\hline Disease site, agent, and line & Reference & Regimen & Outcome \\
\hline \multicolumn{4}{|l|}{ Gastric cancer } \\
\hline \multicolumn{4}{|l|}{ Nivolumab } \\
\hline \multirow[t]{2}{*}{ Second line } & Kang et al., $2017^{19}$ & Nivolumab (3 mg/kg) & mOS: \\
\hline & (ONO-4538-12, abstract) & vs. placebo & $\begin{array}{l}5.32 \text { vs. } 4.14 \text { months } \\
\qquad(p<0.001)\end{array}$ \\
\hline \multicolumn{4}{|l|}{ Merkel cell carcinoma } \\
\hline \multicolumn{4}{|l|}{ Avelumab } \\
\hline \multirow[t]{2}{*}{ Second line } & Kaufman et al., $2016^{20}$ & $\begin{array}{c}\text { Avelumab }(10 \mathrm{mg} / \mathrm{kg}) \\
\text { every } 2 \text { weeks }\end{array}$ & $\begin{array}{c}\text { ORR: } 31.8 \% \\
(95 \% \mathrm{Cl}: 21.9 \text { to } 43.1)\end{array}$ \\
\hline & & & $\begin{array}{c}\text { Response }>6 \text { months } \\
\text { in } 86 \% \text { responders }\end{array}$ \\
\hline
\end{tabular}

$\mathrm{mOS}=$ median overall survival; $\mathrm{HR}$ = hazard ratio; $\mathrm{OS}=$ overall survival; $\mathrm{mPFS}=$ median progression-free survival; $\mathrm{AACR}=\mathrm{American}$ Association for Cancer Research; NR = not reached; SCC = squamous cell carcinoma; ORR = objective response rate; IHC = immunohistochemistry; $\mathrm{RR}=$ relative risk $\mathrm{Cl}=$ confidence interval.

Pembrolizumab and nivolumab, two anti-PD-1 antibodies, have both been associated with survival benefits in second-line therapy for melanoma and, subsequently, in first-line therapy as single agents (Table I). More recently, in the CheckMate 067 study, a combination strategy was used, comparing nivolumab-ipilimumab with either agent alone in previously untreated patients. The study showed that, compared with either agent alone, the combination was associated with significantly higher rates of overall response and progression-free survival $(\mathrm{PFs})^{6}$. The same observation was made for overall survival (os) in a recent update $^{22}$. Currently, the ongoing KeYNOTE-029 study is examining the combination pembrolizumab-ipilimumab in the first line, with early results demonstrating a manageable toxicity profile and an overall response rate of $53 \%^{23}$.

Success with anti-PD-1/PD-L1 antibodies has since been seen in many other common solid tumours. In metastatic NSCLC, nivolumab, pembrolizumab, and atezolizumab have each demonstrated survival benefit in the second line, with pembrolizumab demonstrating a survival benefit in the first line for PDL-1-positive $(\geq 50 \%)$ NSCLC. However, compared with standard chemotherapy, the first-line study with nivolumab did not demonstrate a survival benefit. The reason for the discrepancy is uncertain. Selection of PD-L1 expression greater than $50 \%$ in the pembrolizumab study (compared with greater than $5 \%$ in the nivolumab study) and issues with biomarker testing in the nivolumab trial have been postulated as possible explanations. In advanced renal cell carcinoma (RCC), checkpoint inhibitors have been associated with significant improvement in outcomes, with the phase III CheckMate 025 study demonstrating a survival benefit for second-line treatment with nivolumab ${ }^{18}$.

Immunotherapies have also had significant effects in tumour sites that previously had few available treatment options beyond first-line therapy. Head-and-neck squamous cell carcinomais characterized by geneticinstability, infection with the human papillomavirus, and immune defects, making it a good candidate for immune-based treatments. The CheckMate 141 trial showed benefit with immunotherapy for recurrent or metastatic head-and-neck squamous cell carcinoma with disease progression on or after platinum therapy $^{12}$ (Table I). Pembrolizumab also showed efficacy in patients with recurrent or metastatic head-and-neck squamous cell carcinoma with disease progression on or after platinum-containing chemotherapy. Its accelerated approval was based on the tumour response rate and durability of response seen in the KEYNOTE-012 study (Table I). In a phase IA expansion trial in previously treated metastatic urothelial cancer, atezolizumab was shown to lead to a median PFS of 24 weeks in patients with PD-L1 expression of 2-3 on immunohistochemistry ${ }^{14}$. More recently, nivolumab, pembrolizumab, and durvalumab have all gained U.S. Food and Drug Administration and Health Canada approval for the second-line treatment of urothelial cancer (Table II). In gastroesophageal cancer, the phase III ONO-4538 study presented at the 2017 Gastrointestinal Cancers Symposium showed that nivolumab in the second line or beyond for metastatic gastric cancer improved survival to 5.32 months from 4.14 months with placebo, reducing the risk of death by $37 \%$ [hazard ratio (HR): $0.63 ; p<0.0001]^{19}$. In pretreated advanced malignant mesothelioma, the phase II MAPS2 study demonstrated, after 15 months of follow-up, an impressive median os of 13.6 months in patients receiving nivolum$\mathrm{ab}$; moreover, median os was still not reached in patients receiving ipilimumab-nivolumab ${ }^{24}$.

\section{EMERGING STRATEGIES}

\section{Combination Therapy}

Expression of PD-L1 is known to be a dynamic phenomenon that occurs as a result of tumour cell interaction with immune cells in the tumour microenvironment. Thus, combination treatments that lead to increased expression of PD-L1 with PD-1/PD-L1 checkpoint inhibition, and other potentially synergistic immune strategies, are being explored to induce successful antitumour immune responses. Table III summarizes phase III clinical trials to date that have investigated a combination strategy. 
TABLE II Immunotherapies currently approved the U.S. Food and Drug Administration and Health Canada

\begin{tabular}{|c|c|c|c|c|}
\hline \multirow[t]{2}{*}{ Class and drug } & \multicolumn{4}{|c|}{ Approved indication and date } \\
\hline & Canada & & United States & \\
\hline \multicolumn{5}{|l|}{ Cytokine } \\
\hline Interferon alfa & Melanoma & Jun 2012 & Melanoma & Apr 2011 \\
\hline Interleukin 2 & & & Renal cell carcinoma: metastatic & 1992 \\
\hline \multicolumn{5}{|l|}{ Vaccine } \\
\hline Sipuleucel-T & & & $\begin{array}{l}\text { Prostate cancer: Asymptomatic or minimally } \\
\text { symptomatic metastatic disease }\end{array}$ & Oct 2010 \\
\hline BCG vaccine & Bladder cancer: superficial & May 2013 & Bladder cancer: superficial & Feb 2009 \\
\hline \multicolumn{5}{|l|}{ Oncolytic virus } \\
\hline T-VEC & & & $\begin{array}{c}\text { Melanoma: Unresectable cutaneous, } \\
\text { subcutaneous, nodal lesions after initial surgery } \\
\text { for intratumoural lesions }\end{array}$ & Oct 2015 \\
\hline \multicolumn{5}{|l|}{ Checkpoint inhibitor } \\
\hline \multicolumn{5}{|l|}{ Anti-CTLA-4 } \\
\hline Ipilimumab & $\begin{array}{l}\text { Melanoma: unresectable or } \\
\text { metastatic after failure of, } \\
\text { or intolerance to, other therapy }\end{array}$ & Mar 2012 & Melanoma: unresectable or metastatic & March 2011 \\
\hline \multicolumn{5}{|l|}{ Anti-PD-L1 } \\
\hline \multirow[t]{2}{*}{ Atezolizumab } & $\begin{array}{l}\text { Urothelial cancer: locally } \\
\text { advanced and metastatic }\end{array}$ & Apr 2017 & $\begin{array}{l}\text { Urothelial cancer: metastatic breakthrough } \\
\text { therapy designation, accelerated approval }\end{array}$ & May 2016 \\
\hline & & & NSCLC: metastatic breakthrough therapy & Jun 2016 \\
\hline \multirow[t]{2}{*}{ Avelumab } & & & $\begin{array}{l}\text { Merkel cell carcinoma: metastatic disease, } \\
\text { first line or beyond }\end{array}$ & Mar 2017 \\
\hline & & & $\begin{array}{l}\text { Urothelial cancer: locally advanced or } \\
\text { metastatic, progressed during or after } \\
\text { platinum-containing chemotherapy }\end{array}$ & May 2017 \\
\hline \multirow[t]{2}{*}{ Durvalumab } & $\begin{array}{l}\text { Urothelial cancer: locally } \\
\text { advanced or metastatic, } \\
\text { progressed during or after } \\
\text { platinum-containing chemotherapy }\end{array}$ & Nov 2017 & $\begin{array}{l}\text { Urothelial cancer: locally advanced or } \\
\text { metastatic progressed during or after } \\
\text { platinum-containing chemotherapy }\end{array}$ & May 2017 \\
\hline & & & $\begin{array}{l}\text { NSCLC: locally advanced unresectable } \\
\text { disease that has not progressed after } \\
\text { platinum-based chemoradiation therapy }\end{array}$ & Jul 2107 \\
\hline \multicolumn{5}{|l|}{ Anti-PD1 } \\
\hline \multirow[t]{6}{*}{ Pembrolizumab } & $\begin{array}{l}\text { Melanoma: unresectable or metastatic } \\
\text { before ipilimumab, and disease } \\
\text { progression after ipilimumab, and } \\
\text { if BRAFV600E mutation-positive, } \\
\text { after a BRAF or MEK inhibitor }\end{array}$ & Jun 2016 & $\begin{array}{c}\text { Melanoma: unresectable or metastatic after } \\
\text { progression on ipilimumab, and if } B R A F V 600 \mathrm{E} \\
\text { mutant, a BRAF inhibitor expanded to } \\
\text { initial treatment }\end{array}$ & Sep 2014 \\
\hline & $\begin{array}{l}\text { NSCLC: first line (PD-L1 expression } \\
\geq 50 \% \text {, no EGFR or ALK mutation }\end{array}$ & Apr 2016 & $\begin{array}{l}\text { NSCLC: first line (PD-L1 expression } \geq 50 \% \text { ), } \\
\text { no } E G F R \text { or } A L K \text { mutation }\end{array}$ & Oct 2016 \\
\hline & $\begin{array}{l}\text { NSCLC: second line (PD-L1 }>1 \% \text {, } \\
\text { EGFR or ALK mutation progressing } \\
\text { on targeted agent }\end{array}$ & & $\begin{array}{l}\text { NSCLC: first line in combination with } \\
\text { pemetrexed and carboplatin for previously } \\
\text { untreated metastatic nonsquamous disease }\end{array}$ & May 2017 \\
\hline & $\begin{array}{l}\text { Urothelial cancer: locally advanced or } \\
\text { metastatic, progressed during or after }\end{array}$ & & $\begin{array}{l}\text { NSCLC: second line (PD-L1 }>1 \%), \\
\text { EGFR or } A L K \text { mutated progressing on targeted agent }\end{array}$ & Oct 2015 \\
\hline & platinum-containing chemotherapy & & $\begin{array}{l}\text { Head and neck: recurrent or metastatic } \\
\text { squamous cell carcinoma after progression } \\
\text { on platinum-containing chemotherapy }\end{array}$ & Aug 2016 \\
\hline & & & $\begin{array}{l}\text { Urothelial cancer: locally advanced or } \\
\text { metastatic, progressed during or after } \\
\text { platinum-containing chemotherapy }\end{array}$ & May 2017 \\
\hline
\end{tabular}


TABLE II Continued

\begin{tabular}{|c|c|c|c|c|}
\hline \multirow[t]{2}{*}{ Class and drug } & \multicolumn{4}{|c|}{ Approved indication and date } \\
\hline & Canada & & United States & \\
\hline \multicolumn{5}{|l|}{ Checkpoint inhibitor } \\
\hline \multirow[t]{4}{*}{ Nivolumab } & $\begin{array}{l}\text { Renal cell carcinoma: advanced } \\
\text { or metastatic clear cell renal } \\
\text { carcinoma after prior } \\
\text { antiangiogenic therapy }\end{array}$ & Apr 2016 & $\begin{array}{l}\text { Renal cell carcinoma: advanced or } \\
\text { metastatic after antiangiogenic therapy }\end{array}$ & Nov 2015 \\
\hline & $\begin{array}{l}\text { NSCLC: locally advanced or } \\
\text { metastatic with disease progression } \\
\text { on or after platinum-based } \\
\text { chemotherapy; patients with EGFR } \\
\text { or ALK aberrations should also } \\
\text { receive targeted therapy }\end{array}$ & Feb 2016 & $\begin{array}{l}\text { NSCLC: squamous and nonsquamous } \\
\text { metastatic disease after progression on } \\
\text { first-line chemotherapy }\end{array}$ & Mar 2015 \\
\hline & \multirow{2}{*}{$\begin{array}{l}\text { Head and neck: recurrent or } \\
\text { metastatic, progressing on or } \\
\text { after platinum-based treatment }\end{array}$} & \multirow[t]{2}{*}{ May 2017} & $\begin{array}{l}\text { Head and neck: recurrent or metastatic } \\
\text { progressing on or after platinum-based treatment }\end{array}$ & Nov 2016 \\
\hline & & & $\begin{array}{l}\text { Urothelial cancer: locally advanced or metastatic, } \\
\text { progressing on platinum-containing chemotherapy }\end{array}$ & Feb 2017 \\
\hline
\end{tabular}

BCG = bacillus Calmette-Guérin.

Increasing evidence now supports activation of the immune system as one of the contributing mechanisms of effect for cytotoxic chemotherapy. Cell death and subsequent antigen release is postulated to lead to immune stimulation, priming the tumour for immune-mediated therapies. That hypothesis provides the rationale for several studies that have combined immune agents with chemotherapy. Available phase II evidence in lung cancer demonstrates that a phased approach in which chemotherapy is administered before a checkpoint inhibitor is introduced leads to better outcomes. The KEYNOTE-021 phase II study showed that pembrolizumab combined with carboplatin and pemetrexed is tolerable and associated with improved PFs in treatment-naïve patients with nonsquamous NCLC $^{28}$. That finding supports the hypothesis that, when cell death caused by cytotoxic agents "releases antigens," immune response with subsequent immune checkpoint blockade is enabled. In addition, the phased approach is associated with a more favourable toxicity profile. Yet despite the promising phase II studies, a phase III study of combination chemotherapy with ipilimumab for extensive-stage small-cell lung cancer failed to show a benefit in os or in any secondary endpoint ${ }^{25,29}$.

Combining anti-CTLA- 4 and anti-PD-1 therapies has been shown to be associated with meaningful survival improvements, and combinations are being actively studied in multiple tumour sites (Table III). Inhibition of cTLA-4 activates T-cell immune responses, leading to a potentially synergistic effect with PD-1/PD-L1 inhibitors. At the 2017 meeting of the American Association for Cancer Research, early os data from the CheckMate 067 study examining nivolumabipilimumab compared with either agent used singly in metastatic melanoma were presented. Compared with ipilimum$\mathrm{ab}$, the combination was associated with a $45 \%$ reduction in the risk of death (HR: $0.55 ; p<0.0001$ ), and compared with nivolumab, a $12 \%$ reduction was observed (HR: $0.99 ; p=$ nonsignificant). That lack of statistical significance in survival could have been a result of patients in the monotherapy arm being treated with active agents such as ipilimumab in the second-line setting. Although combination strategies are effective, significant toxicities are also observed with their use, particularly when anti-CTLA- 4 or cytotoxic agents are included. The CheckMate 012 study looked at the safety and tolerability of an alternative lower dose for ipilimumab when combined with nivolumab in patients with NSCLC, ultimately moving to a dose of $1 \mathrm{mg} / \mathrm{kg}$ every 6 weeks from the $3 \mathrm{mg} / \mathrm{kg}$ dose used for the phase III CheckMate 227 study. Similar dosing was used in the phase III CheckMate 214 study (Table III) and, overall, was well tolerated.

Not all tumour sites have seen success with singleagent immune checkpoint blockade. In a phase III study, ipilimumab failed to demonstrate benefit compared with placebo in metastatic castrate-resistant prostate cancer ${ }^{30}$. Combining the immune checkpoint inhibitors with cancer vaccines could, however, be a potential strategy to overcome that barrier. A phase I study combining GVAX (Aduro Biotech, Berkeley, CA, U.S.A.), a vaccine made using allogeneic tumour cells transfected with granulocytemacrophage colony-stimulating factor, with ipilimumab showed responses in the level of prostate-specific antigen, with a tolerable side-effect profile ${ }^{31}$. In another phase I study, Prostvac (Bavarian Nordic, Kvistgaard, Denmark) was combined with increasing doses of ipilimumab, again demonstrating responses in the level of prostate-specific antigen. Success with the GVAX vaccine has also been seen in pancreatic cancer. In a phase II study, os was improved to 9.7 months from 4.6 months when GVAX was combined with CRS-207 (live attenuated Listeria monocytogenes expressing mesothelin) ${ }^{32}$. Toxicity associated with that approach also appears to be favourable, with $20 \%$ of patients experiencing grade 3 or 4 toxicities, as opposed to the $50 \%$ or more seen with combinations of ipilimumab and PD-1 inhibitor. Table IV shows select vaccine combination studies that are currently underway for solid tumours. 
TABLE III Phase III combination studies with immune checkpoint inhibitors

\begin{tabular}{|c|c|c|c|c|}
\hline Reference (trial name) & Disease & Regimen & Outcome & Toxicity \\
\hline Robert et al., $2011^{1}$ & $\begin{array}{l}\text { Metastatic melanoma, } \\
\text { first line }\end{array}$ & $\begin{array}{l}\text { Dacarbazine } \\
\text { plus ipilimumab } \\
\text { vs. } \\
\text { dacarbazine }\end{array}$ & $\begin{array}{l}\text { mOS: } \\
11.2 \text { vs. } 9.1 \text { months } \\
\text { (HR: } 0.72 ; p=0.001)\end{array}$ & $\begin{array}{l}\text { Grades } 3-4 \text { toxicity: } \\
56.3 \% \text { vs. } 27.5 \% \\
(p<0.001)\end{array}$ \\
\hline $\begin{array}{l}\text { Larkin et al., 20156 } \\
\text { (CheckMate 067) }\end{array}$ & $\begin{array}{l}\text { Metastatic melanoma, } \\
\text { first line }\end{array}$ & $\begin{array}{l}\text { Nivolumab } \\
\text { plus ipilimumab } \\
\text { vs. } \\
\text { nivolumab } \\
\text { vs. } \\
\text { ipilimumab }\end{array}$ & $\begin{array}{c}\text { mPFS: } \\
11.5 \text { vs. } 6.9(p<0.001) \\
\text { vs. } 2.9(p<0.001) \text { months } \\
\text { PD-L1-positive: } 14.0 \text { months } \\
\text { (combination and nivolumab) } \\
\text { PD-L1-negative: } 11.2 \text { vs. } 5.3 \text { months } \\
\text { (combination vs. nivolumab) }\end{array}$ & $\begin{array}{c}\text { Grades } 3-4 \text { toxicity: } \\
55 \% \text { vs. } 27.3 \% \text { vs. } 16.3 \% \\
\text { Adverse events leading to } \\
\text { discontinuation: } \\
35.4 \% \text { vs. } 14.8 \% \text { vs. } 7.7 \%\end{array}$ \\
\hline Reck et al., $2016^{25}$ & $\begin{array}{l}\text { Early-stage SCLC, } \\
\text { first line }\end{array}$ & $\begin{array}{l}\text { Etoposide-platinum } \\
\text { plus ipilimumab } \\
\text { vs. } \\
\text { etoposide-platinum }\end{array}$ & $\begin{array}{c}\text { mOS: } \\
11.0 \text { vs. } 10.9 \text { months (NS) } \\
\text { mPFS: } \\
4.6 \text { vs. } 4.4 \text { months (NS) }\end{array}$ & \\
\hline $\begin{array}{l}\text { Escudier et al., 2017²6 } \\
\text { (CheckMate 214) }\end{array}$ & $\begin{array}{l}\text { Metastatic RCC, } \\
\text { first line }\end{array}$ & $\begin{array}{l}\text { Nivolumab } \\
\text { plus ipilimumab } \\
\text { vs. } \\
\text { sunitinib }\end{array}$ & $\begin{array}{c}\text { mPFS: } \\
11.6 \text { vs. } 8.4 \text { months }(p=0.0331) \\
\text { mOS: } \\
\text { NR vs. } 26 \text { months }(p<0.0001) \\
\text { in poor- and intermediate-risk patients }\end{array}$ & $\begin{array}{c}\text { Grades } 3-5 \text { toxicity: } \\
46 \% \text { vs. } 63 \%\end{array}$ \\
\hline $\begin{array}{l}\text { Motzer et al., 201827 } \\
\text { (IMmotion151) }\end{array}$ & $\begin{array}{l}\text { Metastatic RCC, } \\
\text { first line }\end{array}$ & $\begin{array}{l}\text { Atezolizumab } \\
\text { plus bevacizumab } \\
\text { vs. } \\
\text { sunitinib }\end{array}$ & $\begin{array}{c}\text { mPFS, PD-L1-positive ( }>1 \% \text { expression): } \\
11.2 \text { vs. } 7.7 \text { months ( } p=0.02) \\
\text { mPFS, PD-L1-negative: } \\
11.2 \text { vs. } 8.4 \text { months }(p=0.02)\end{array}$ & $\begin{array}{c}\text { Grades } 3-4 \text { toxicity: } \\
40 \% \text { vs. } 54 \%\end{array}$ \\
\hline
\end{tabular}

$\mathrm{mOS}=$ median overall survival; $\mathrm{HR}=$ hazard ratio; $\mathrm{mPFS}=$ median progression-free survival; $\mathrm{SCLC}=$ small-cell lung cancer; NS = nonsignificant; $\mathrm{RCC}=$ renal cell carcinoma; $\mathrm{NR}=$ not reached.

TABLE IV Select studies of cancer vaccine combinations currently underway

\begin{tabular}{lcc}
\hline \multicolumn{1}{c}{ Name } & ClinicalTrials.gov ID & \multicolumn{1}{c}{ Status } \\
\hline $\begin{array}{l}\text { GVAX pancreas vaccine (with CY) and CRS-207 with or without nivolumab } \\
\text { Multiple class I peptides and montanide ISA 51 VG with escalating doses of anti-PD-1 antibody } \\
\text { BMS936558 }\end{array}$ & NCT02243371 & Active, not recruiting \\
$\begin{array}{l}\text { Study of nivolumab in combination with GM.CD40L vaccine in adenocarcinoma of the lung } \\
\begin{array}{l}\text { Vaccine therapy and pembrolizumab in treating patients with hormone-resistant, } \\
\text { metastatic prostate cancer }\end{array}\end{array}$ & NCT02466568 & NCT02499835 not recruiting \\
$\begin{array}{l}\text { Nivolumab with DC vaccines for recurrent brain tumours } \\
\text { Immunization strategy with intra-tumoural injections of Pexa-Vec with ipilimumab in metastatic } \\
\text { or advanced solid tumours }\end{array}$ & NCT02529072 Active, not recruiting \\
A Phase I/II trial to evaluate a peptide vaccine plus ipilimumab in patients with melanoma & NCT02385669 & Recruiting \\
\hline
\end{tabular}

\section{Early Disease}

To date, most of the evidence to support immune-based therapies has been developed in advanced or metastatic disease. In melanoma, before the introduction of immune checkpoint inhibitors, immune therapy in the form of interferon alfa-2b was considered a standard therapy option for patients with high-risk resected disease ${ }^{33-35}$. Although a benefit in disease-free survival was seen, no os benefit was observed. More recently, ipilimumab was shown to have both relapse-free survival and os benefit when compared with placebo in the European Organisation for Research and Treatment 18071 trial in stage III cutaneous melanoma. Relapse-free survival was significantly better (5-year rate: $18.3 \%$ vs. $38.9 \%$ ), and os was prolonged (5-year rate: $65.4 \%$ vs. $54.4 \%)^{36}$. However, rates of toxicity were high, with adverse events of any grade being observed in $98.7 \%$ of patients, and grade 3 or 4 events in $54.1 \%$. Only $29 \%$ of patients were able to complete more than 1 year of therapy. Currently, two adjuvant studies in high-risk disease that have completed accrual are awaiting results: the Eastern Cooperative Oncology Group 1609 trial comparing ipilimumab with interferon alfa-2b as adjuvant treatment in high-risk disease (see NCT01274338 at http://ClinicalTrials.gov/), and the CheckMate 238 trial comparing ipilimumab with nivolumab (NCT02388906). Another study is underway to 
examine nivolumab and pembrolizumab for the adjuvant treatment of melanoma (NCT02362594).

In other tumour sites, trials are currently underway to assess the role for immune-based agents in the curative setting. The PACIFIC study, which is evaluating 1 year of durvalumab after curative-intent chemoradiation in patients with stage III NSCLC, showed an increase in PFs to 16.8 months from 5.6 months (HR: $0.52 ; 95 \%$ confidence interval: 0.42 to 0.65$)^{37}$. In a separate study, nivolumab was shown to be safe and feasible in early-stage NSCLC in the neoadjuvant setting. Before surgical resection, patients with stages I-IIIA NSCLC $(n=18)$ received doses of nivolumab at 4 weeks and then at 2 weeks. In 7 patients (39\%), major pathologic responses $(<10 \%$ residual viable tumour) were associated with immune infiltration of the tumour. One patient experienced a complete pathologic response ${ }^{38}$. Neoadjuvant strategies are also being examined in multiple tumour sites, but questions about the optimal strategy remain. Whether dual checkpoint blockade would be more effective in the neoadjuvant setting is unclear.

\section{PRACTICAL CONSIDERATIONS}

\section{Response Criteria}

The patterns of response observed with immunotherapy agents might be different from those observed with traditional cytotoxic chemotherapeutics or molecularly targeted agents. Patients might experience a transient worsening of disease that would be characterized as progression by traditional response criteria, followed by stability or improvement. Compared with the response to cytotoxic therapies, responses to immunotherapies can also take longer to become clinically apparent and can be durable well beyond the induction period. Hypotheses as to why this "pseudoprogression" occurs include the homing of cytotoxic T lymphocytes into the tumour; increase of the inflammatory milieu, causing a transient enlargement of the tumour mass and associated regional lymph nodes; and fast-growing tumours, which might increase in size before the treatment effect begins ${ }^{39}$.

This situation made it imperative that a separate set of criteria for evaluating immune response be used in trials of efficacy to avoid early discontinuation of a potentially effective agent. Wolchok et al $^{39}$ thus proposed new immune-related response criteria (irRc) to accurately and reproducibly measure the efficacy of immune agents (Table v). The criteria are based on three main principles. First, rather than target lesions, total tumour burden is used to determine quantity of disease. Second, confirmation at least 4 weeks after first documentation of any response other than stable disease is required. Finally, new lesions do not necessarily represent progressive disease. Instead, those lesions are included into the whole tumour burden, and their significance depends on confirmation. For instance, in an analysis of KEYNOTE-001 evaluating pembrolizumab in metastatic melanoma, atypical responses were observed. A comparison of the irRc with the Response Evaluation Criteria in Solid Tumors (RECIST, version 1.1) showed that, based on survival analysis, RECIST might underestimate benefit in approximately $15 \%$ of patients ${ }^{40}$. In a further effort to standardize evaluation in clinical trials, the immune RECIST (iRECIST) was written based on expert opinion and consensus, including all available knowledge about response dynamics ${ }^{41}$. The iREcIsT also incorporates pseudoprogression and allows for new lesions (standard RECIST version 1.1 does not). The new criteria remain to be validated; they are still being created based on the initial trial data currently being collected.

Certain challenges in using the irRc remain, however. Tumour burden is based on the sum of the products of all target lesions (World Health Organization criteria, in which the product of the longest measured perpendicular diameter is used for each target lesion), which has high inter-observer variability in practice. Additionally, the new criteria were developed based on responses to anti-CTLA-4 and anti-PD-1/PD-L1 monoclonal antibodies in malignant melanoma. Those drugs promote an adaptive response through clonal expansion of CD4+ or CD8+ lymphocytes, which supports massive infiltration as the source of pseudoprogression ${ }^{42}$. In a cohort of 56 patients with advanced NSCLC treated with nivolumab alone, responses were noted in the same 8 patients whether irRc or RECIST 1.1 was used, and no case of pseudoprogression was noted $^{43}$. Whether the irRc is or is not as important in the context of other immune-based therapies with alternative mechanisms of action is not clear.

\section{Predictors of Response to Immune-Based Therapy}

Although the benefits of immune-based therapies have been significant, the fact remains that only a portion of patients derive benefit. How best to select those patients has yet to be determined.

The biomarker that has been the most broadly studied is PD-L1 expression (in trials of PD-1/PDL-1 checkpoint inhibitors). Although using PD-L1 expression intuitively makes sense, several limitations are associated with this biomarker. Expression of PD-L1 and PD-1 is dynamic, and it changes in relation to local cytokines and other factors, including prior systemic therapies. Additionally, the threshold that separates "positive" from "negative" is variable depending on the analysis, and the different assays that measure expression yield discordant results ${ }^{44}$. Overall, however, most trials evaluating PD-L1 status show trends of increasing response rates with increasing expression ${ }^{5,6,45}$.

The utility of PD-L1 as a predictive biomarker has been most consistent with pembrolizumab in the setting of lung cancer. Currently, PD-L1 immunohistochemistry staining is the only diagnostic approved by the U.S. Food and Drug Administration for patients with NscLC treated with pembrolizumab and, based on the inclusion criteria in KEYNOTE-024, that staining has to be $50 \%$ or greater in patients treated in the first line. With nivolumab, the relationship has been less clear. A correlation was demonstrated in CheckMate 057, which evaluated nivolumab in the second line for nonsquamous NSCLC, but CheckMate 017 (for squamous NSCLC) showed no relationship between the various PD-L1 positivity cut-offs $(1 \%, 5 \%$, or $10 \%)$ and response rate, $\mathrm{PFs}$, or $\mathrm{os}^{7,8}$. However, in the study evaluating combined ipilimumab-nivolumab in the first line for NSCLC, a predictive utility of PD-Ll was observed. In patients with PD-L1-positive tumours, nivolumab alone was equivalent to the combination, with a median PFs of 
TABLE V Comparison between World Health Organization (WHO) criteria and the immune-related response criteria (irRC) ${ }^{39}$

\begin{tabular}{|c|c|c|}
\hline \multirow[t]{2}{*}{ Variable } & \multicolumn{2}{|c|}{ Applicable criteria } \\
\hline & WHO & irRC \\
\hline New, measureable lesions ${ }^{a}$ & Always represent progressive disease & Incorporated into tumour burden \\
\hline New, non-measurable lesions ${ }^{b}$ & Always represent progressive disease & $\begin{array}{l}\text { Do not define progression (but preclude } \\
\text { immune-related complete response) }\end{array}$ \\
\hline Non-index lesions & $\begin{array}{c}\text { Changes contribute to defining best overall response } \\
\text { of complete response, partial response, stable disease, } \\
\text { or progressive disease }\end{array}$ & $\begin{array}{l}\text { Contribute to defining immune-related complete } \\
\text { response (complete disappearance required) }\end{array}$ \\
\hline Complete response & $\begin{array}{c}\text { Disappearance of all lesions in } 2 \text { consecutive observations } \\
\text { not less than } 4 \text { weeks apart }\end{array}$ & $\begin{array}{l}\text { Disappearance of all lesions in } 2 \text { consecutive } \\
\text { observations not less than } 4 \text { weeks apart }\end{array}$ \\
\hline Partial response & $\begin{array}{l}\geq 50 \% \text { Decrease in the sum of products of diameters of } \\
\text { all index lesions compared with baseline in } 2 \text { observations } \\
\text { at least } 4 \text { weeks apart, in absence of new lesions or } \\
\text { unequivocal progression of non-index lesion }\end{array}$ & $\begin{array}{l}\geq 50 \% \text { Decrease in tumour burden compared } \\
\text { with baseline in } 2 \text { observations at least } \\
4 \text { weeks apart }\end{array}$ \\
\hline Stable disease & $\begin{array}{l}50 \% \text { Decrease in the sum of products of diameters compared } \\
\text { with baseline cannot be established, nor a } 25 \% \text { increase } \\
\text { compared with nadir in the absence of new lesions, } \\
\text { or equivocal progression of non-index lesions }\end{array}$ & $\begin{array}{l}50 \% \text { Decrease in tumour burden compared } \\
\text { with baseline cannot be established, } \\
\text { nor a } 25 \% \text { increase compared with nadir }\end{array}$ \\
\hline Progressive disease & $\begin{array}{c}\text { Any or all of at least a } 25 \% \text { increase in the sum of products } \\
\text { of diameters compared with nadir, or unequivocal } \\
\text { progression of non-index lesions, or appearance of } \\
\text { new lesions (at any single time point) }\end{array}$ & $\begin{array}{c}\text { At least } 25 \% \text { increase in tumour burden } \\
\text { compared with nadir (at any single time point) } \\
\text { in } 2 \text { consecutive observations at least } \\
4 \text { weeks apart }\end{array}$ \\
\hline
\end{tabular}

a $\geq 5 \times 5 \mathrm{~mm}$.

b $<5 \times 5 \mathrm{~mm}$.

14.0 months in both arms. In contrast, the combination was superior in PD-L1-negative patients, reaching a median PFS of 11.2 months compared with 5.23 months for nivolumab alone, thus identifying a potential biomarker for the group that benefits from combination therapy.

Based on the inconsistency observed with PD-L1, alternative biomarkers are being sought to predict response to therapy. Clonality of T-cell receptors has been exploredspecifically, the association between CD8 and PD-1/PDL1 expression. Expression of CD8+, PD-1, and PD-L1 was significantly associated with response to pembrolizumab treatment in patients with metastatic melanoma ${ }^{46}$. Those findings were supported in a study of patients with muscleinvasive bladder cancer, which found a correlation between a greater number of somatic mutations and a lower T-cell receptor diversity index. Those tumours had a greater CD8+:FOxP3 ratio, indicating specific CD8+ clonal expansion and antitumour immune responses.

Emerging data support the hypothesis that tumour mutational burden (TмB) and genomic instability lead to higher responses to immune therapies. In NSCLC, smoking history is correlated with increased mutational burden ${ }^{47}$ and has been shown to correlate with increased rates of response to $\mathrm{PD}-\mathrm{L} 1$ inhibitors ${ }^{48}$. In a more recent study, whole-exome sequencing of patients with NscLc treated with pembrolizumab revealed an association between тмв and improved overall response rate, PFs, and durable clinical benefit ${ }^{48}$. Tumours reliant on only 1 driver mutation, such as EGFR activating mutation-positive lung cancers, have a consistently low response rate to immunomodulating agents. In an exploratory analysis that used whole-exome sequencing to look at тмв in specimens from patients enrolled in the CheckMate 026 study in NSCLC, patients with a high тмв were shown, compared with their counterparts having a low TMB, to experience superior PFS. Similar findings from the CheckMate 032 study in smallcell lung cancer were recently presented. That phase I/II study examined nivolumab compared with nivolumabipilimumab in previously treated metastatic disease. In both treatment arms, response rates and 1-year survival were both higher in patients with a high тмв. In a recent analysis that combined available тмв data from 27 different cancer types, a strong correlation was demonstrated between high тмв and response to checkpoint inhibition ${ }^{49}$.

\section{Duration of Therapy}

One of the unique features of immune therapy is the durability of the responses observed. Thus, the appropriate treatment duration remains uncertain. Ipilimumab received regulatory approval for use in melanoma based on second-line studies in which the drug was given for 4 doses, with no maintenance. No randomized studies have addressed the potential role of maintenance. The 4-dose strategy was subsequently used in the studies combining ipilimumab with nivolumab for melanoma and NSCLC.

With the optimal duration of therapy for checkpoint inhibitors remaining unknown, these agents are currently given continuously until disease progression or until limiting toxicity. Updated follow-up from the KEYNOTE-010 trial of pembrolizumab in NSCLC showed that os was maintained. In an analysis of the 47 patients who completed 2 years of pembrolizumab and stopped treatment, $90 \%$ experienced an ongoing response. Follow-up even after therapy stop showed that only 2 patients (4\%) experienced 
disease progression during that time, suggesting that even after therapy stops, clinical benefit can be observed. That observation was further supported by the 5 -year follow-up of the phase I CA209-003 study of nivolumab in advanced NSCLC, which reported an estimated 5-year os rate of $16 \%$, with ongoing clinical benefit even after cessation of thera$\mathrm{py}^{50}$. Those studies led to the randomized CheckMate 153 study, which randomized patients with advanced NSCLC and at least 1 prior line of systemic therapy to either 1-year or continuous treatment with nivolumab. Data from the first 220 patients showed that continuous treatment is superior for PFs, with a HR of 0.42 (95\% confidence interval: 0.25 to 0.71 ) and a trend toward superior os (HR: 0.63 ). Based on those data, continuous treatment was established as the standard of care.

There remains a population of patients that might sustain benefit from a shorter duration of treatment. One proposed strategy to select those patients is to determine duration based on minimal residual disease $\mathrm{e}^{51}$. Although data to support that approach are limited, a study in NSCLC measured PD-L1-positive circulating tumour cells (CTCS) at baseline and at 3 and 6 months. At baseline and 3 months, the presence of PD-L1-positive cTCs was found to be associated with poor patient outcomes. At 6 months after treatment, all patients who still had PD-L1-positive CTCs experienced progressive disease; those with PD-L1negative cтcs obtained clinical benefit ${ }^{52}$.

\section{Economic Impact}

Although the clinical benefit of immune therapies is clear, questions about the cost-effectiveness of the approach remain. In advanced melanoma, the inhibitors ipilimum$\mathrm{ab}$, nivolumab, and pembrolizumab have all demonstrated cost-effectiveness ${ }^{53-55}$. For other tumour sites, costeffectiveness is less clear. A Canadian cost-effectiveness analysis of nivolumab compared with docetaxel or erlotinib as second-line therapy for NSCLC showed that nivolumab cost, respectively, an additional $\$ 151,560$ or $\$ 140,601$ per quality-adjusted life-year ${ }^{56}$.

In a recent review article by Tartari et al. ${ }^{57}$, the perpatient estimated costs for pembrolizumab and nivolumab were estimated for melanoma, NSCLC, and RCC. To calculate the per-patient cost, the cost of each drug per milligram was used to determine a monthly cost (based on a weight of $70 \mathrm{~kg}$ ). Pembrolizumab was estimated, based on dose and schedule, to cost $\$ 23,017$ and $\$ 20,716$ per patient per month in melanoma and NSCLC respectively. Nivolumab was estimated to cost $\$ 12,682, \$ 12,600$, and $\$ 6,984$ per patient per month in melanoma, NSCLC, and RCC respectively. Using the median PFs from the clinical trials and the World Health Organization's estimate of new cases worldwide per annum, the annual cost was calculated. For pembrolizumab, that total reached $\$ 3.8$ billion in melanoma and $\$ 83.9$ billion in NSCLC for 1 year. For nivolumab, the total cost was $\$ 1.7$ billion, $\$ 27.3$ billion, and $\$ 2.7$ billion for melanoma, NSCLC, and RCC respectively. That study highlights the paradox for successful immunotherapeutics, which become less cost-effective as the duration for which they are required lengthens. It also clearly reveals the effect of disease incidence, with NSCLC having a significantly higher incidence than either melanoma or RCC.

\section{CONCLUSIONS}

Immunotherapies are currently revolutionizing the treatment of solid tumours. In a series of practice-changing trials, they have delivered meaningful survival improvements for patients with (previously) poor-prognosis cancers and for certain cancer types in which therapeutic options were limited. Many aspects of their use, including optimal combinations, sequencing, duration, and clinical setting, remain to be clarified. Ongoing clinical trials will serve to further increase their role, but careful consideration must be given to finding the safest, most individualized, and most cost-effective way to incorporate them into cancer care.

\section{CONFLICT OF INTEREST DISCLOSURES}

We have read and understood Current Oncology's policy on disclosing conflicts of interest, and we declare that we have no competing interests relevant to this article.

\section{AUTHOR AFFILIATIONS}

*Tom Baker Cancer Centre, Calgary, AB; ${ }^{\dagger} \mathrm{CHUM}-$ Hôpital Notre-Dame, Montreal, QC; ${ }^{\ddagger}$ London Health Sciences Centre, London, ON; ${ }^{\circledR}$ BC Cancer, Vancouver, BC; ${ }^{\prime}$ University Health Network, Princess Margaret Hospital, Toronto, ON; ${ }^{\#}$ Cross Cancer Institute, Edmonton, $\mathrm{AB}$.

\section{REFERENCES}

1. Robert C, Thomas L, Bondarenko I, et al. Ipilimumab plus dacarbazine for previously untreated metastatic melanoma. N Engl J Med 2011;364:2517-26.

2. Hodi FS, O'Day SJ, McDermottDF, et al. Improved survival with ipilimumab in patients with metastatic melanoma. $N$ Engl J Med2010;363:711-23. [Erratumin: NEnglJMed 2010;363:1290]

3. Robert C, Schachter J, Long GV, et al. Pembrolizumab versus ipilimumab in advanced melanoma. $N$ Engl J Med 2015;372:2521-32.

4. Ribas A, Puzanov I, Dummer R, et al. Pembrolizumab versus investigator-choice chemotherapy for ipilimumab-refractory melanoma (кеуNOте-002): a randomised, controlled, phase 2 trial. Lancet Oncol 2015;16:908-18.

5. Robert C, Long GV, Brady B, et al. Nivolumab in previously untreated melanoma without BRAF mutation. N Engl J Med 2015;372:320-30.

6. Larkin J, Chiarion-Sileni V, Gonzalez R, et al. Combined nivolumab and ipilimumab or monotherapy in untreated melanoma. N Engl J Med 2015;373:23-34.

7. Brahmer J, Reckamp KL, Baas P, et al. Nivolumab versus docetaxel in advanced squamous-cell non-small-cell lung cancer. N Engl J Med 2015;373:123-35.

8. Borghaei H, Paz-Ares L, Horn L, et al. Nivolumab versus docetaxel in advanced nonsquamous non-small-cell lung cancer. N Engl J Med 2015;373:1627-39.

9. Reck M, Rodríguez-Abreu D, Robinson AG, et al. on behalf of the Keynote-024 investigators. Pembrolizumab versus chemotherapy for PD-L1-positive non-small-cell lung cancer. N Engl J Med 2016;375:1823-33.

10. Herbst RS, Baas P, Kim DW, et al. Pembrolizumab versus docetaxel for previously treated, PD-L1-positive, advanced non-small-cell lung cancer (KEYNOTE-010): a randomised controlled trial. Lancet 2016;387:1540-50.

11. Rittmeyer A, Barlesi F, Waterkamp D, et al. on behalf of the OAK study group. Atezolizumab versus docetaxel in patients with previously treated non-small-cell lung cancer (OAK): a phase 3, open-label, multicentre randomised controlled trial. Lancet 2017;389:255-65. 
12. Ferris RL, Blumenschein G Jr, Fayette J, et al. Nivolumab for recurrent squamous-cell carcinoma of the head and neck. $N$ Engl J Med 2016;375:1856-67.

13. Seiwert TY, Burtness B, Mehra R, et al. Safety and clinical activity of pembrolizumab for treatment of recurrent or metastatic squamous cell carcinoma of the head and neck (KEYNOTE-012): an open-label, multicentre, phase 1B trial. Lancet Oncol 2016;17:956-65.

14. Powles T, Eder JP, Fine GD, et al. MPDL3280A (anti-PD-L1) treatment leads to clinical activity in metastatic bladder cancer. Nature 2014;515:558-62.

15. Sharma P, Retz M, Siefker-Radtke A, et al. Nivolumab in metastatic urothelial carcinoma after platinum therapy (CheckMate 275): a multicentre, single-arm, phase 2 trial. Lancet Oncol 2017;18:312-22.

16. Bellmunt J, de Wit R, Vaughn DJ, et al. on behalf of the KeYNOTE-045 investigators. Pembrolizumab as second-line therapy for advanced urothelial carcinoma. $N$ Engl J Med 2017;376:1015-26.

17. Powles T, O'Donnell PH, Massard C, et al. Updated efficacy and tolerability of durvalumab in locally advanced or metastatic urothelial carcinoma [abstract 286]. J Clin Oncol 2017;35:. [Available online at: http://ascopubs.org/doi/ abs/10.1200/JCO.2017.35.6_suppl.286; cited 15 July 2018]

18. Motzer RJ, Escudier B, McDermott DF, et al. on behalf of the CheckMate 025 investigators. Nivolumab versus everolimus in advanced renal-cell carcinoma. NEnglJ Med 2015;73:1803-13.

19. Kang YK, Satoh T, Ryu MH, et al. Nivolumab (ono-4538/BMs936558) as salvage treatment after second or later-line chemotherapy for advanced gastric or gastroesophageal junction cancer (AGC): a double-blinded, randomized, phase III trial [abstract 2].JClin Oncol 2017;35:. [Available online at: http:// ascopubs.org/doi/abs/10.1200/JCO.2017.35.4_suppl.2; cited 15 July 2018]

20. Kaufman HL, Russell J, Hamid O, et al. Avelumab in patients with chemotherapy-refractory metastatic Merkel cell carcinoma: a multicentre, single-group, open-label, phase 2 trial. Lancet Oncol 2016;17:1374-85.

21. Atkins MB, Lotze MT, Dutcher JP, et al. High-dose recombinant interleukin 2 therapy for patients with metastatic melanoma: analysis of 270 patients treated between 1985 and 1993. J Clin Oncol 1999;17:2105-16.

22. Wolchok JD, Chiarion-Sileni V, Gonzalez R, et al. Overall survival with combined nivolumab and ipilimumab in advanced melanoma. N Engl J Med 2017;377:1345-56.

23. Long GV, Atkinson V, Cebon JS, et al. Standard-dose pembrolizumab in combination with reduced-dose ipilimumab for patients with advanced melanoma (KеуNoTE-029): an open-label, phase 1B trial. Lancet Oncol 2017;18:1202-10.

24. Scherpereel A, Mazieres J, Greillier L, et al. Second or 3rd line nivolumab (Nivo) versus Nivo plus ipilimumab (Ipi) in malignant pleural mesothelioma (MPM) patients: results of IFCT1501 MAPS2 randomized phase II trial [abstract LBA8507]. $J$ Clin Oncol 2017;35:. [Available online at: http://ascopubs. org/doi/abs/10.1200/JCO.2017.35.18_suppl.LBA8507; cited 16 July 2018]

25. Reck M, Luft A, Szczesna A, et al. Phase III randomized trial of ipilimumab plus etoposide and platinum versus placebo plus etoposide and platinum in extensive-stage small-cell lung cancer. J Clin Oncol 2016;34:3740-8.

26. Escudier B, Tannir N, McDermott DF, et al. CheckMate 214: efficacy and safety of nivolumab + ipilimumab v sunitinib for treatment-naïve advanced or metastatic renal cell carcinoma, including IMDC risk and PD-L1 expression subgroups [abstract LBA5]. Ann Oncol 2017:28(suppl 5):. [Available online at: https://academic.oup.com/annonc/article/28/ suppl_5/mdx440.029/4109941; cited 16 July 2018]
27. Motzer RJ, Powles T, Atkins MB, et al. IMmotion151: a randomized phase III study of atezolizumab plus bevacizumab vs sunitinib in untreated metastatic renal cell carcinoma (mRCC) [abstract 578].JClin Oncol 2018;36:. [Available online at: http:// ascopubs.org/doi/abs/10.1200/JCO.2018.36.6_suppl.578; cited 16 July 2018]

28. Lynch TJ, Bondarenko I, Luft A, et al. Ipilimumab in combination with paclitaxel and carboplatin as first-line treatment in stage IIIB/IV non-small-cell lung cancer: results from a randomized, double-blind, multicenter phase II study. JClin Oncol 2012;30:2046-54.

29. Reck M, Bondarenko I, Luft A, et al. Ipilimumab in combination with paclitaxel and carboplatin as first-line therapy in extensive-disease-small-cell lung cancer: results from a randomized, double-blind, multicenter phase 2 trial. Ann Oncol 2013;24:75-83.

30. Kwon ED, Drake CG, Scher HI, et al. on behalf of the CA184043 investigators. Ipilimumab versus placebo after radiotherapy in patients with metastatic castration-resistant prostate cancer that had progressed after docetaxel chemotherapy (CA184-043): a multicentre, randomised, double-blind, phase 3 trial. Lancet Oncol 2014;15:700-12.

31. Madan RA, Mohebtash M, Arlen PM, et al. Ipilimumab and a poxviral vaccine targeting prostate-specific antigen in metastatic castration-resistant prostate cancer: a phase 1 dose-escalation trial. Lancet Oncol 2012;13:501-8.

32. Le DT, Wang-Gillam A, Picozzi V, et al. Safety and survival with GVAX pancreas prime and Listeria monocytogenesexpressing mesothelin (CRS-207) boost vaccines for metastatic pancreatic cancer. J Clin Oncol 2015;33:1325-33.

33. Eggermont AM, Suciu S, MacKie R, et al. on behalf of the EORTC Melanoma Group. Post-surgery adjuvant therapy with intermediate doses of interferon alfa $2 \mathrm{~b}$ versus observation in patients with stage IIв/III melanoma (ЕоRTC 18952): randomised controlled trial. Lancet 2005;366:1189-96.

34. Eggermont AM, Suciu S, Testori A, et al. Long-term results of the randomized phase III trial EORTC 18991 of adjuvant therapy with pegylated interferon alfa- $2 \mathrm{~b}$ versus observation in resected stage III melanoma. J Clin Oncol 2012;30:3810-18.

35. Mocellin S, Pasquali S, Rossi CR, Nitti D. Interferon alpha adjuvant therapy in patients with high-risk melanoma: a systematic review and meta-analysis. J Natl Cancer Inst 2010;102:493-501.

36. Eggermont AM, Chiarion-Sileni V, Grob JJ, et al. Adjuvant ipilimumab versus placebo after complete resection of highrisk stage III melanoma (EORTC 18071): a randomised, double-blind, phase 3 trial. Lancet Oncol 2015;16:522-30. [Errata in: Lancet Oncol 2015;16:e262 and Lancet Oncol 2016;17:e223]

37. Antonia S, Goldberg SB, Balmanoukian A, et al. Safety and antitumour activity of durvalumab plus tremelimumab in non-small cell lung cancer: a multicentre, phase 1B study. Lancet Oncol 2016;17:299-308.

38. Forde PM, Smith KN, Chaft JE, et al. Neoadjuvant anti-PD1, nivolumab, in early stage resectable non-small cell lung cancer [abstract LBA41_PR]. Ann Oncol 2016;27(suppl 6):. [Available online at: https://academic.oup.com/annonc/ article/27/suppl_6/LBA41_PR/2800547; cited 16 July 2018]

39. Wolchok JD, Hoos A, O'Day S, et al. Guidelines for the evaluation of immune therapy activity in solid tumors: immunerelated response criteria. Clin Cancer Res 2009;15:7412-20.

40. Hodi FS, Hwu WJ, Kefford R, et al. Evaluation of immunerelated response criteria and RECIST vl.1 in patients with advanced melanoma treated with pembrolizumab. J Clin Oncol 2016;34:1510-17.

41. Seymour L, Bogaerts J, Perrone A, et al, irecist: guidelines for response criteria for use in trials testing immunotherapeutics. Lancet Oncol 2017;18:e143-52. 
42. Merlano M, Occelli M, Garrone O. Immune-related response criteria: light and shadows. ESMO Open 2016;1:e000082.

43. Nishino M, Ramaiya NH, Chambers ES, et al. Immunerelated response assessment during PD-1 inhibitor therapy in advanced non-small cell lung cancer patients. JImmunother Cancer 2016;4:84.

44. Chae YK, Pan A, Davis AA, et al. Biomarkers for PD-1/PD-L1 blockade therapy in non-small-cell lung cancer: is PD-L1 expression a good marker for patient selection? Clin Lung Cancer 2016;17:350-61.

45. Weber JS, Kudchadkar RR, Yu B, et al. Safety, efficacy, and biomarkers of nivolumab with vaccine in ipilimumabrefractory or -naive melanoma. JClin Oncol 2013;31:4311-18.

46. Weber JS, D'Angelo SP, Minor D, et al. Nivolumab versus chemotherapy in patients with advanced melanoma who progressed after anti-CTLA-4 treatment (CheckMate 037): a randomised, controlled, open-label, phase 3 trial. Lancet Oncol 2015;16:375-84.

47. Govindan R, Ding L, Griffith M, et al. Genomic landscape of non-small cell lung cancer in smokers and never-smokers. Cell 2012;150:1121-34.

48. Herbst RS, Soria JC, Kowanetz M, et al. Predictive correlates of response to the anti-PD-L1 antibody MPDL3280A in cancer patients. Nature 2014;515:563-7.

49. Yarchoan M, Hopkins A, Jaffee EM. Tumor mutational burden and response rate to PD-1 inhibition. $N$ Engl J Med 2017;377:2500-1.

50. Spigel DR, Reynolds C, Waterhouse D, et al. Phase $1 / 2$ study of the safety and tolerability of nivolumab plus crizotinib for the first-line treatment of $A L K$ translocation-positive advanced non-small cell lung cancer (CheckMate 370). J Thorac Oncol 2018;13:682-8.

51. El Rassy E, Assi T, Kattan J. Is minimal residual disease a convincing tool to determine the treatment duration of immune checkpoint inhibitors? Future Oncol 2017;3:381-3.

52. Nicolazzo C, Raimondi C, Mancini ML, et al. Monitoring PD-L1 positive circulating tumor cells in non-small cell lung cancer patients treated with the PD-1 inhibitor nivolumab. Sci Rep 2016;6:31726.

53. Barzey V, Atkins MB, Garrison LP, Asukai Y, Kotapati S, Penrod JR. Ipilimumab in 2nd line treatment of patients with advanced melanoma: a cost-effectiveness analysis. J Med Econ 2013;16:202-12.

54. Bohensky MA, Pasupathi K, Gorelik A, Kim H, Harrison JP, Liew D. A cost-effectiveness analysis of nivolumab compared with ipilimumab for the treatment of BRAF wild-type advanced melanoma in Australia. Value Health 2016;19:1009-15.

55. Wang J, Chmielowski B, Pellissier J, Xu R, Stevinson K, Liu FX. Cost-effectiveness of pembrolizumab versus ipilimumab in ipilimumab-naïve patients with advanced melanoma in the United States. J Manag Care Spec Pharm 2017;23:184-94.

56. Goeree R, Villeneuve J, Goeree J, Penrod JR, Orsini L, Tahami Monfared AA. Economic evaluation of nivolumab for the treatment of second-line advanced squamous NscLC in Canada: a comparison of modeling approaches to estimate and extrapolate survival outcomes. J Med Econ 2016;19:630-44.

57. Tartari F, Santonib M, Burattini L, et al. Economic sustainability of anti-PD-1 agents nivolumab and pembrolizumab in cancer patients: recent insights and future challenges. Cancer Treat Rev 2016;48:20-4. 